\section{Research Square}

Preprints are preliminary reports that have not undergone peer review.

They should not be considered conclusive, used to inform clinical practice, or referenced by the media as validated information.

\title{
Association of Benzodiazepines With SARS-CoV-2 Infection and Clinical Outcomes: a Nationwide Cohort Study
}

\author{
Hye Yoon Park \\ Department of Psychiatry, Yonsei University College of Medicine, Severance Hospital, Seoul \\ Junhyun Kwon \\ Institute of Health Services Research, Yonsei University, Seoul \\ Suk Kyoon An ( $\sim$ ansk@yuhs.ac) \\ Department of Psychiatry, Yonsei University College of Medicine, Severance Hospital, Seoul \\ Eun-Cheol Park \\ Department of Preventive Medicine, Yonsei University College of Medicine, Seoul
}

\section{Research Article}

Keywords: benzodiazepine, SARS-CoV-2 infection, COVID-19, hospitalization, mortality

Posted Date: March 7th, 2022

DOI: https://doi.org/10.21203/rs.3.rs-1349278/v1

License: () (1) This work is licensed under a Creative Commons Attribution 4.0 International License. Read Full License 


\begin{abstract}
The evidence for the impact of benzodiazepine (BZD) use on infection or clinical outcomes of severe acute respiratory syndrome coronavirus 2 (SARS-CoV-2) is limited. We evaluated the association of BZD use with SARS-CoV-2 infection and the clinical outcomes of coronavirus disease 2019 (COVID-19) using a nationwide COVID-19 database from South Korea. This nationwide cohort study was performed using the COVID-19 database from the Health Insurance Review and Assessment Service of Korea, and SARS-CoV-2 positivity was investigated according to BZD use. SARS-CoV-2-positive adult patients were assessed in three groups, those who needed hospitalization, those with severe symptoms requiring intensive care, and those who died. A multivariate logistic regression model was used for all the analyses. After adjusting for potential confounding factors, there was no association between BZD use and SARS-CoV-2 positivity. SARS-CoV-2-positive patients with BZD use showed an increased risk of need for hospitalization from COVID-19 compared to those without BZD use (odds ratio [OR]: 1·33, 95\% confidence interval [CI]: 1·07-1·65). In addition, there was a higher risk for long-term users (OR: 2·64, 95\% Cl: 1·08-6·47). Chronic BZD use contributed to a higher risk of the need for hospitalization among COVID-19 patients, whereas BZD use did not increase the risk of SARSCoV-2 test positivity, severe outcomes, or mortality.
\end{abstract}

\title{
Introduction
}

The coronavirus disease (COVID-19) pandemic is causing a global crisis. COVID-19 is caused by severe acute respiratory syndrome coronavirus 2 (SARS-CoV2), with consequences ranging from asymptomatic disease to death. ${ }^{1}$ However, $14 \%$ of SARS-CoV-2-positive patients show severe disease, and $5 \%$ show critical health conditions; ${ }^{2}$ the risk of mortality (0.1\%) associated with COVID-19 is much higher than that associated with seasonal influenza. ${ }^{3}$ Various risk factors such as age $\geq 65$ years, chronic obstructive pulmonary disease (COPD), asthma, hypertension, cardiovascular disease, chronic kidney disease, diabetes, obesity, malignancy, immunosuppressant use and transplantation, and chronic human immunodeficiency virus (HIV) infection have been identified. ${ }^{3}$

Benzodiazepines (BZD) and BZD receptor agonists have been known to increase the risk of pneumonia and death due to pneumonia. 4,5 There is also concern about the risk of respiratory depression by BZD use in people with pre-existing respiratory problems, although reports have been conflicting; an increased risk of respiratory exacerbations was reported for patients with COPD, ${ }^{6}$ while associations of BZD use with hospital admission or impaired blood gases were not significant in COPD patients. ${ }^{7}$ A few recent studies on the characteristics of severe COVID-19 cases ${ }^{8-10}$ have focused on the use of BZD. However, the results have been inconsistent.

Given the high prevalence $(2 \cdot 6-23 \cdot 7 \%)$ of BZD use, ${ }^{11-16}$ investigating the impact of BZD use on infection or clinical outcomes of SARS-CoV-2 is beneficial for public health. Here, we assessed the association of BZD use with SARS-CoV-2 positivity and clinical outcomes in three groups of patients, those in need of hospital admission, those with severe symptoms requiring intensive care, and those who died, using a nationwide cohort data from South Korea.

\section{Methods}

\section{Study design and population}

In this study, National Health Information Database (NHID)-COVID data provided by the National Health Insurance Service (NHIS) were used; data pertaining to the period from 2015 to 2020 were obtained. The dataset included data from patients with COVID-19 who tested positive from January 1 to May $30,2020$. Control groups included general controls and subjects who showed negative SARS-CoV-2 test results.

There are two different study population in this study. Study population 1 is to examine the association between benzodiazepine use and SARS-CoV-2 test positivity, and study population 2 is to investigate the association between benzodiazepine use and clinical outcomes in SARS-CoV-2-positive patients. The initial population for the year 2020 included a total of 351,377 subjects. These were categorized into 8,070 patients with SARS-CoV-2, and 343,307 controls. After excluding those with missing values, 328,373 subjects remained. They were divided into two different groups according to whether BZD was used or not: 52,151 subjects used BZD and 276,222 subjects did not use BZD. Using the 1:1 propensity score matching (PSM) method, 52,151 participants each from the case group and the control group were selected as the final study subjects (out of a total of 104,302 subjects). In addition, a total of 7,596 patients with COVID-19 were divided into two groups according to whether BZD used or not: 1,074 subjects used BZD and 6,522 subjects did not use BZD (Fig. 1). All methods were performed in accordance with the relevant guidelines and regulations.

\section{Measures}

\section{Outcome variables}

In this study, we set SARS-Cov-2 test positivity and clinical outcomes as the outcome variables. The clinical outcomes for SARS-CoV-2-positive patients consisted of three variables: hospital admission, severe symptoms requiring intensive care or invasive ventilation, and mortality. Patients who died before receiving hospital care were also included in the first group, as it was assumed that they needed hospital admission.

\section{Variables of interest}

The study subjects were divided into two groups according to BZD use. Use of BZD was defined based on claim history in 2019, one year before the outbreak of COVID-19 in 2020.

BZD categories were based on the following main ingredient codes: clobazam (135702ATB), clonazepam (136401ATB), chlordiazepoxide (131201ATB, 131202ATB, 255800ATB), diazepam (142930BIJ), flunitrazepam (160601ATB), flurazepam (161801ATB), ethyl loflazepate (156201ATB, 156202ATB), 
alprazolam (105501ATB, 105502ATB, 105504ATB, 105505ATB, 105507ATB), bromazepam (118501ATB), clotiazepam (137302ATB), etizolam (156501ATB, 156502ATB, 156503ATB), lorazepam (185501ATB, 185504ATB), tofisopam (241201ATB), and triazolam (243501ATB, 243502ATB). In addition, chronic BZD use was categorized based on a 90-day usage period and a 180-day usage period within a year. ${ }^{16,17}$

\section{Covariates}

In this study, we adjusted for variables that could directly or indirectly affect outcomes, including basic independent variables such as sex, age, and residential area. The residential areas were grouped based on the major regions and the metropolitan areas where the incidence of COVID-19 was high in Korea at that time (Seoul, Gyeonggi-do, Daegu, and Gyeongbuk); the rest of the regions were combined into a single group. Type of insurance coverage was classified into three different groups: workplace, local, and medical benefits. Participants' clinical baseline characteristics were also considered as covariates. The Charlson Comorbidity Index (CCI) was used to confirm the patients' comorbidity status in 2019, which was the year prior to the COVID-19 outbreak. Based on CCI data, the severity of comorbidity was categorized as 0,1 , or $2+$. Additionally, we reviewed the disease records for the period from 2015 to 2018 for diabetes, cardiovascular disease, cerebrovascular disease, COPD, asthma, hypertension, and chronic kidney disease, which could be associated with worse clinical outcomes and BZD use.

\section{Statistical analysis}

We investigated the results after 1:1 PSM; in this method, the case and control participants who have a similar propensity score values are matched. ${ }^{18}$ We matched case and control groups by including age, sex, and CCl variables as parameters in the propensity score model. The association between BZD use and SARS-CoV-2 positivity was examined in a total of five models. Model 1 was a crude model for the association between BZD use and SARS-CoV-2 positivity; model 2 was a minimally adjusted model adjusted for age and sex; model 3 was the fully adjusted model, which was adjusted for age, sex, residential area, type of insurance coverage, $\mathrm{CCl}$, and disease history (diabetes, cardiovascular disease, cerebrovascular disease, COPD, asthma, hypertension, and chronic kidney disease); model 4 was the fully adjusted model for the association between the chronic use of BZD for 90 days and SARS-CoV-2 positivity; and model 5 was the fully adjusted model for the association between the chronic use of BZD for 180 days and SARS-CoV-2 positivity. Among patients who tested positive for SARS-CoV-2, Pearson's chi-square tests were used to compare the sociodemographic and clinical characteristics with respect to BZD use and chronic BZD use. To examine the association of BZD use and the chronic BZD use with the risk of SARS-CoV-2 positivity and clinical outcomes, we used multivariable logistic regression models after adjusting for sex, age, residential area, $\mathrm{CCl}$, and disease history.

All the statistical analyses were performed using SAS statistical software version 9.4 (Statistical Analysis System Institute, Cary, NC, USA).

\section{Results}

The characteristics of the study participants are shown in Table 1. A total of 328,373 individuals were divided into two groups as follows: those who did not use BZD $(n=276,222)$ and those who used BZD $(n=52,151)$. The two groups were matched by propensity scoring, and 52,151 propensity-matched pairs were defined (eTable 1). Of the total subjects, 145,758 (44.4\%) were men and 182,615 (55.6\%) were women. A majority of the participants (84.1\%) was aged $20-39$ years; $31 \cdot 1 \%$ were in the $40-59$ age group. Comorbidities were recorded in 193,945 (59.1\%) individuals, while no comorbidities were observed in 134,428 (40.9\%) individuals.

Table 2 shows the association between BZD use and the risk of SARS-CoV-2 positivity; we identified these associations before and after adjusting for potential confounders. After PSM, there was no association between BZD use and the risk of SARS-CoV-2 positivity (model 1: odds ratio [OR]: 1.01, 95\% confidence interval [Cl]: $0 \cdot 93-1 \cdot 10$, model 2: OR: 1·01, 95\% Cl: 0.93-1·10, model 3: OR: 1·09, 95\% Cl: 1·00-1·20). Moreover, model 4 and 5 showed that there were no associations between chronic BZD use and the risk of SARS-CoV-2 positivity (model 4: OR: 0.94, Cl: 0.81 - 1·10, model 5: OR: 0.99, Cl: 0.83 - 1·18).

Table 3 shows the distribution of the study population who tested positive for SARS-CoV-2. Of 7,596 individuals, 1,074 (14.1\%) used BZD and 6,522 (85.9\%) did not use BZD. Of the BZD use group, $59(5 \cdot 5 \%)$ individuals died, $111(10 \cdot 3 \%)$ needed intensive care or invasive ventilation, and $939(87 \cdot 4 \%)$ were in need of hospitalization.

Figure 2 shows the association between BZD use and the clinical outcomes of COVID-19 among patients who tested positive for SARS-CoV-2. After adjusting for potential cofounding variables, the risk of need for hospitalization due to COVID-19 was higher in those with BZD use that in those without BZD use (OR: $1 \cdot 33,95 \% \mathrm{Cl}: 1 \cdot 07-1 \cdot 65)$. In addition, the risk of need for hospitalization was higher in COVID-19 patients who used BZD for more than 180 days than in those who did not use BZD (OR: $2 \cdot 64,95 \% \mathrm{Cl}: 1 \cdot 08-6 \cdot 47)$.

\section{Discussion}

Using a nationwide cohort database from South Korea, in this study, we showed that the chronic use of BZD contributed to an increase in the risk of the need for hospitalization among COVID-19 patients. However, BZD use did not significantly influence the risk of SARS-CoV-2 positivity, severe outcomes, or mortality.

In animal studies, BZD increased mortality due to a variety of bacterial infections ${ }^{19-22}$ and bacterial superinfections related to influenza. ${ }^{19}$ In human subjects, controversy persists regarding a causal connection between BZD use and infections. ${ }^{23}$ The association between BZD use and the increased need for hospitalization in this study may be in line with previous studies which showed increased susceptibility to superinfections in influenza-infected animals ${ }^{24}$ and humans. ${ }^{5}$ The underlying mechanism may be related to the effects of BZD on the immune system; BZD amplifies the effect of the gamma-aminobutyric acid receptor in immune cells, which may lead to an immune-suppressant profile. ${ }^{24}$ Regarding the long term use of BZD, chronic consumption of BZD was related to the appearance of modified lymphocyte subsets. ${ }^{25,26}$ However, relatively few cases of severe COVID-19 and inaccessible variables in our data, such as the dosage of BZD, may require replication of pharmacoepidemiologic research on the relationship between BZD and COVID-19. 
Recent studies on the association between mental illness and COVID-19 outcomes have shown a higher risk for severe COVID-19 outcomes in patients with a mental illness, though the analyses did not include adjustment for BZD use. ${ }^{27,28}$ Since BZD is frequently prescribed for anxiety symptoms and sleep disturbances, our findings suggest that BZD use should be considered in further studies on the relationship between mental illness and COVID-19 outcomes. Likewise, adjusting for mental illness in future studies in the association between BZD and COVID-19 outcomes would uncover the risk of BZD use regardless of psychiatric diagnoses. However, it is interesting to note that $87.7 \%$ of BZD prescriptions were related to non-psychiatric diagnoses in a nationwide cohort study from South Korea. ${ }^{16}$

Due to limited medical resources, especially with reference to negative pressure beds, policies on the priority for hospitalization among COVID-19 patients have been amended. For example, South Korea has introduced a residential treatment center to isolate asymptomatic patients or patients who do not need hospital care. Therefore, patients with moderate-to-severe symptoms may be hospitalized first. ${ }^{29}$ In this regard, the results of this nationwide cohort study may be applied to efficiently set strategies for managing COVID-19 patients, based the finding that patients with chronic BZD use need to be monitored frequently due to a high risk of need for hospitalization; however, the strategies should also consider our finding that BZD use does not imply increased severity of clinical outcomes related to COVID-19.

Some limitations of this study should be acknowledged. Although a validation study showed the overall agreement of diagnosis at $82 \cdot 0 \%$, ${ }^{30}$ outcomes were identified by diagnostic and procedural codes, and possible misclassifications cannot be ruled out. Moreover, data about the indication and BZD dose, as well as the hospitalization period were unavailable, which precluded a full assessment. The use of nationwide longitudinal data strengthens the causal relationship established in our study, and the generalizability of our findings. However, we could not include all the COVID-19 patients up to the present, and thus may have missed analyzing new clinical outcomes that may have resulted due to various mutations in SARS-CoV- 2 .

In summary, BZD use was not associated with the risk of SARS-CoV-2 positivity, severe outcomes, or mortality. However, BZD use, especially for more than 180 days, conferred a higher risk of need for hospitalization among COVID-19 patients. Health professionals and public health authorities need to be alert about patients with long-term use of BZD, and these patients need to be closely monitored even if they currently do not need hospital care.

\section{Declarations}

\section{Ethics approval and consent to participate}

The data were anonymized before they were obtained; thus, informed consent was not required. The Yonsei University Institutional Review Board approved this study (Approval number: 4-2020-1240).

\section{Consent for publication}

Not applicable

\section{Availability of data and materials}

The data that support the findings of this study are available from the National Health Insurance Service in South Korea but restrictions apply to the availability of these data, which were used under license for the current study, and so are not publicly available. Data are however available from the authors upon reasonable request and with permission of the National Health Insurance Service in South Korea.

\section{Competing interests}

There are no conflicts of interest to declare.

\section{Funding}

This work was supported by the Basic Science Research Program through the National Research Foundation of Korea (NRF) funded by the Ministry of Science, ICT \& Future Planning, Republic of Korea (grant number 2017R1A2B3008214). The funder of the study had no role in the study design; data collection, analysis, and interpretation; writing the report; and the decision to submit the paper for publication.

\section{Authors' contributions}

H.Y.P. and J.K. designed the study and drafted the manuscript. H.Y.P. is responsible for study concept and design. J.K. took responsibility for acquisition, analysis, or interpretation of data. H.Y.P., J.K., S.K.A., and E.C.P. contributed to the discussion and reviewed and edited the manuscript. S.K.A. and E.C.P. are the guarantors of this work and as such, had full access to all study data. S.K.A. and E.C.P. assume responsibility for the integrity of the data and the accuracy of the data analysis.

\section{Acknowledgments}

Not applicable

\section{References}

1. Wiersinga, W. J., Rhodes, A., Cheng, A. C., Peacock, S. J. \& Prescott, H. C. Pathophysiology, transmission, diagnosis, and treatment of coronavirus disease 2019 (COVID-19): a review. Jama 324, 782-793 (2020). 
2. Wu, Z. \& McGoogan, J. M. Characteristics of and important lessons from the coronavirus disease 2019 (COVID-19) outbreak in China: summary of a report of 72314 cases from the Chinese Center for Disease Control and Prevention. Jama 323, 1239-1242 (2020).

3. Jordan, R. E., Adab, P. \& Cheng, K. (British Medical Journal Publishing Group, 2020).

4. Obiora, E., Hubbard, R., Sanders, R. D. \& Myles, P. R. The impact of benzodiazepines on occurrence of pneumonia and mortality from pneumonia: a nested case-control and survival analysis in a population-based cohort. Thorax 68, 163-170 (2013).

5. Nakafero, G., Sanders, R. D., Nguyen-Van-Tam, J. S. \& Myles, P. R. The association between benzodiazepines and influenza-like illness-related pneumonia and mortality: a survival analysis using UK Primary Care data. Pharmacoepidemiology and Drug Safety 25, 1263-1273, doi:https://doi.org/10.1002/pds.4028 (2016).

6. Vozoris, N. T. et al. Benzodiazepine use among older adults with chronic obstructive pulmonary disease. Drugs \& aging 30, 183-192 (2013).

7. Ekström, M. P., Bornefalk-Hermansson, A., Abernethy, A. P. \& Currow, D. C. Safety of benzodiazepines and opioids in very severe respiratory disease: national prospective study. Bmj 348 (2014).

8. Genet, B. et al. COVID-19 In-Hospital Mortality and Use of Renin-Angiotensin System Blockers in Geriatrics Patients. Journal of the American Medical Directors Association 21, 1539-1545, doi:10.1016/j.jamda.2020.09.004 (2020).

9. Poblador-Plou, B. et al. Baseline Chronic Comorbidity and Mortality in Laboratory-Confirmed COVID-19 Cases: Results from the PRECOVID Study in Spain. International journal of environmental research and public health 17, 5171, doi:10.3390/ijerph17145171 (2020).

10. Reilev, M. et al. Characteristics and predictors of hospitalization and death in the first 11122 cases with a positive RT-PCR test for SARS-CoV-2 in Denmark: a nationwide cohort. International journal of epidemiology 49, 1468-1481 (2020).

11. Mellinger, G. D., Balter, M. B. \& Uhlenhuth, E. H. Insomnia and its treatment: prevalence and correlates. Archives of general psychiatry 42, 225-232 (1985).

12. Ohayon, M. M., Caulet, M., Priest, R. G. \& Guilleminault, C. Psychotropic medication consumption patterns in the UK general population. Journal of clinical epidemiology 51, 273-283 (1998).

13. Chong, Y., Fryar, C. D. \& Gu, Q. Prescription sleep aid use among adults: United States, 2005-2010. (US Department of Health and Human Services, Centers for Disease Control and ..., 2013).

14. Olfson, M., King, M. \& Schoenbaum, M. Benzodiazepine use in the United States. JAMA psychiatry 72, 136-142 (2015).

15. Cunningham, C. M., Hanley, G. E. \& Morgan, S. Patterns in the use of benzodiazepines in British Columbia: examining the impact of increasing research and guideline cautions against long-term use. Health policy 97, 122-129 (2010).

16. Oh, S.-H. et al. In-depth investigation for prescribing trends of benzodiazepines in South Korea. Int J Clin Pharmacol Ther 52, 460-470 (2014).

17. Bushnell, G. A., Stürmer, T., Gaynes, B. N., Pate, V. \& Miller, M. Simultaneous Antidepressant and Benzodiazepine New Use and Subsequent Long-term Benzodiazepine Use in Adults With Depression, United States, 2001-2014. JAMA Psychiatry 74, 747-755, doi:10.1001/jamapsychiatry.2017.1273 (2017).

18. Rosenbaum, P. R. \& Rubin, D. B. The central role of the propensity score in observational studies for causal effects. Biometrika 70, 41-55, doi:10.1093/biomet/70.1.41 (1983).

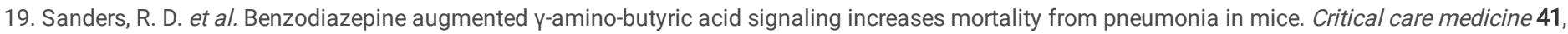
1627 (2013)

20. Laschi, A., Descotes, J., Tachon, P. \& Evreux, J. Adverse influence of diazepam upon resistance to Klebsiella pneumoniae infection in mice. Toxicology letters 16, 281-284 (1983).

21. Domingues-Junior, M., Pinheiro, S., Guerra, J. \& Palermo-Neto, J. Effects of treatment with amphetamine and diazepam on Mycobacterium bovis-induced infection in hamsters. Immunopharmacology and immunotoxicology 22, 555-574 (2000).

22. Galdiero, F. et al. Effects of benzodiazepines on immunodeficiency and resistance in mice. Life sciences 57, $2413-2423$ (1995).

23. Brandt, J. \& Leong, C. Benzodiazepines and Z-drugs: an updated review of major adverse outcomes reported on in epidemiologic research. Drugs in R\&D 17, 493-507 (2017).

24. Sanders, R. D. et al. Immune cell expression of GABAA receptors and the effects of diazepam on influenza infection. Journal of neuroimmunology 282, 97-103 (2015)

25. Lechin, F. et al. Peripheral blood immunological parameters in long-term benzodiazepine users. Clinical neuropharmacology 17, 63-72, doi:10.1097/00002826-199402000-00007 (1994).

26. Cosentino, M. et al. Assessment of lymphocyte subsets and neutrophil leukocyte function in chronic psychiatric patients on long-term drug therapy. Progress in Neuro-Psychopharmacology and Biological Psychiatry 20, 1117-1129, doi:https://doi.org/10.1016/S0278-5846(96)00100-5 (1996).

27. Jeon, H. L., Kwon, J. S., Park, S. H. \& Shin, J. Y. Association of mental disorders with SARS-CoV-2 infection and severe health outcomes: nationwide cohort study. The British journal of psychiatry : the journal of mental science, 1-8, doi:10.1192/bjp.2020.251 (2021).

28. Lee, S. W. et al. Association between mental illness and COVID-19 susceptibility and clinical outcomes in South Korea: a nationwide cohort study. The lancet. Psychiatry 7, 1025-1031, doi:10.1016/s2215-0366(20)30421-1 (2020).

29. Ladner, D., Katsumasa, H. \& Kyuri, K. The Republic of Korea's first 70 days of responding to the COVID-19 outbreak. Global Delivery Initiative, Case Study 13 (2020).

30. Park, E. et al. Assessment of level of agreement in disease codes between health insurance claims data and medical records. Wonju: Health Insurance Review and Assessment service (2018)

\section{Tables}

Page 5/13 
Table 1. General characteristics of the study population 


\begin{tabular}{|c|c|c|}
\hline \multirow[t]{2}{*}{ Variables } & \multicolumn{2}{|c|}{ Overall participants } \\
\hline & $\mathbf{N}$ & $\%$ \\
\hline Total & 328,373 & $100 \cdot 0$ \\
\hline \multicolumn{3}{|c|}{ Benzodiazepine use } \\
\hline No & 276,222 & $84 \cdot 1$ \\
\hline Yes & 52,151 & $15 \cdot 9$ \\
\hline \multicolumn{3}{|l|}{ Age } \\
\hline $20-39$ & 121,707 & $37 \cdot 1$ \\
\hline $40-59$ & 102,102 & $31 \cdot 1$ \\
\hline $60-79$ & 77,042 & $23 \cdot 5$ \\
\hline $80+$ & 27,522 & $8 \cdot 4$ \\
\hline \multicolumn{3}{|l|}{ Sex } \\
\hline Male & 145,758 & $44 \cdot 4$ \\
\hline Female & 182,615 & $55 \cdot 6$ \\
\hline \multicolumn{3}{|l|}{ Residential Area } \\
\hline Seoul & 54,069 & $16 \cdot 5$ \\
\hline Gyeonggi-do & 101,327 & $30 \cdot 9$ \\
\hline Daegu & 57,779 & $17 \cdot 6$ \\
\hline Gyeongbuk & 27,271 & $8 \cdot 3$ \\
\hline Others & 87,927 & $26 \cdot 8$ \\
\hline \multicolumn{3}{|c|}{ Type of Insurance Coverage } \\
\hline $\mathrm{NHI}$ (community) & 79,799 & $24 \cdot 3$ \\
\hline NHI (workplace) & 232,470 & $70 \cdot 8$ \\
\hline Medical aid & 16,104 & $4 \cdot 9$ \\
\hline \multicolumn{3}{|l|}{$\mathrm{CCl}$} \\
\hline 0 & 134,428 & $40 \cdot 9$ \\
\hline 1 & 154,646 & $47 \cdot 1$ \\
\hline $2+$ & 39,299 & $12 \cdot 0$ \\
\hline \multicolumn{3}{|c|}{ History of Diabetes } \\
\hline No & 266,827 & $81 \cdot 3$ \\
\hline Yes & 61,546 & $18 \cdot 7$ \\
\hline \multicolumn{3}{|c|}{ History of Cardiovascular Disease } \\
\hline No & 300,582 & $91 \cdot 5$ \\
\hline Yes & 27,791 & $8 \cdot 5$ \\
\hline \multicolumn{3}{|c|}{ History of Cerebrovascular Disease } \\
\hline No & 301,142 & $91 \cdot 7$ \\
\hline Yes & 27,231 & $8 \cdot 3$ \\
\hline \multicolumn{3}{|l|}{ History of COPD } \\
\hline No & 316,520 & $96 \cdot 4$ \\
\hline Yes & 11,853 & $3 \cdot 6$ \\
\hline \multicolumn{3}{|l|}{ History of Asthma } \\
\hline No & 271,097 & $82 \cdot 6$ \\
\hline Yes & 57,276 & $17 \cdot 4$ \\
\hline
\end{tabular}




\begin{tabular}{|lcc|}
\hline No & 241,649 & $73 \cdot 6$ \\
\hline Yes & 86,724 & $26 \cdot 4$ \\
\hline History of Chronic Kidney Disease & & $97 \cdot 5$ \\
\hline No & 320,270 & $2 \cdot 5$ \\
\hline Yes & 8,103 & \\
\hline NHI: National health insurance, CCl: Charlson Comorbidity Index, COPD: chronic obstructive pulmonary disease \\
\hline All individual characteristics were surveyed as of 2020, and the last survey was recorded until the end of May 2020. \\
\hline
\end{tabular}

Table 2. The results of the analysis of the association between benzodiazepine use and severe acute respiratory syndrome coronavirus 2 (SARS-CoV-2) positivity after $1: 1$ propensity score matching 


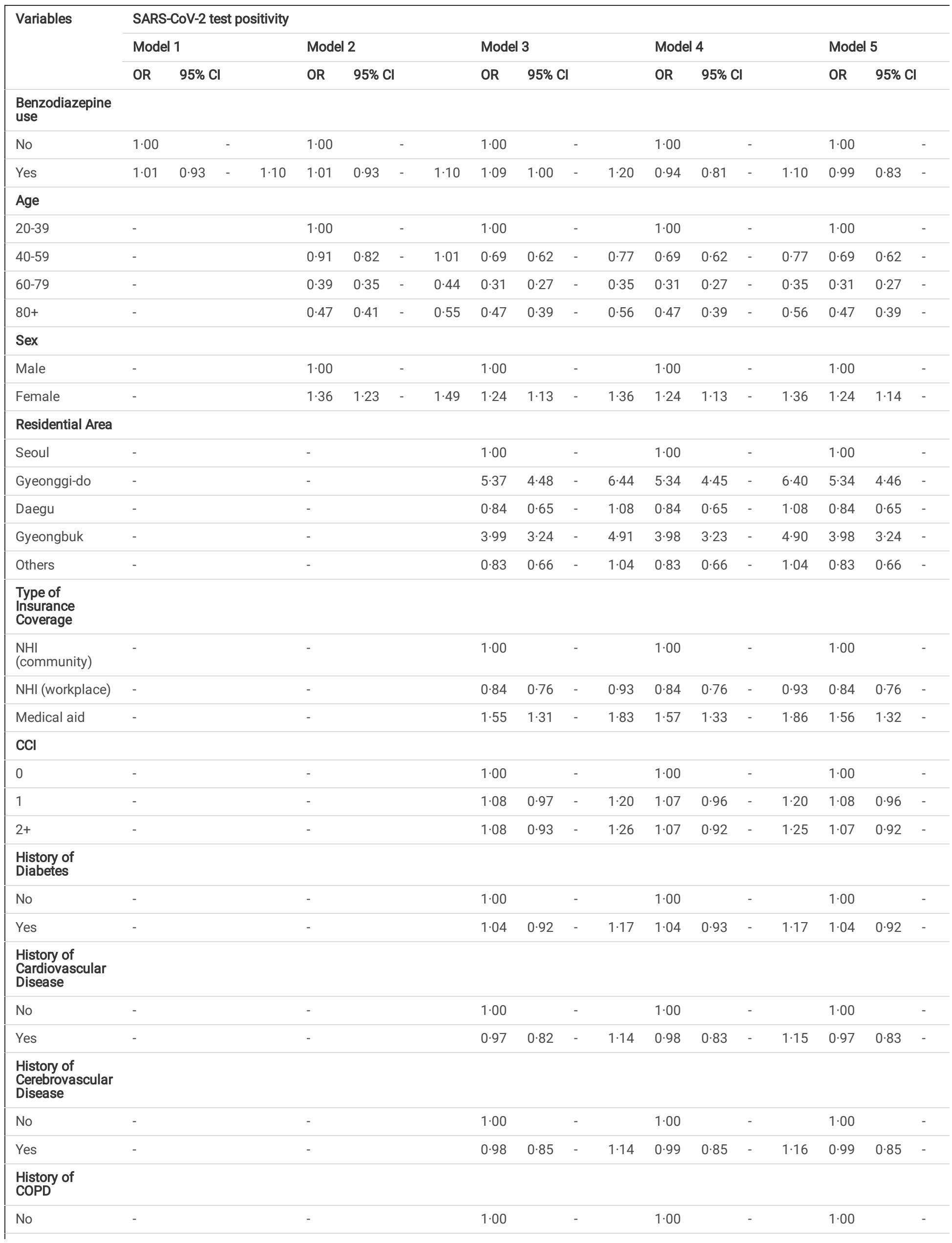




\begin{tabular}{|c|c|c|c|c|c|c|c|c|c|c|c|c|c|}
\hline Yes & - & - & 0.87 & 0.68 & - & $1 \cdot 11$ & 0.87 & 0.68 & - & $1 \cdot 11$ & 0.87 & 0.68 & - \\
\hline \multicolumn{14}{|c|}{$\begin{array}{l}\text { History of } \\
\text { Asthma }\end{array}$} \\
\hline No & - & - & $1 \cdot 00$ & & - & & 1.00 & & - & & 1.00 & & - \\
\hline Yes & - & - & 0.94 & 0.84 & - & 1.05 & 0.95 & 0.85 & - & 1.06 & 0.95 & 0.85 & - \\
\hline \multicolumn{14}{|c|}{$\begin{array}{l}\text { History of } \\
\text { Hypertension }\end{array}$} \\
\hline No & - & - & 1.00 & & - & & 1.00 & & - & & 1.00 & & - \\
\hline Yes & - & - & 1.03 & 0.92 & - & $1 \cdot 16$ & 1.04 & 0.92 & - & $1 \cdot 17$ & 1.03 & 0.92 & - \\
\hline \multicolumn{14}{|c|}{$\begin{array}{l}\text { History of } \\
\text { Chronic Kidney } \\
\text { Disease }\end{array}$} \\
\hline No & - & - & 1.00 & & - & & 1.00 & & - & & $1 \cdot 00$ & & - \\
\hline Yes & - & - & 0.72 & 0.51 & - & 1.02 & $0 \cdot 71$ & 0.50 & - & $1 \cdot 01$ & $0 \cdot 71$ & 0.50 & - \\
\hline
\end{tabular}

NHI: National health insurance, CCl: Charlson Comorbidity Index, COPD: chronic obstructive pulmonary disease

Model 1: crude model; Model 2: minimally adjusted; Model 3: fully adjusted; Model 4: chronic use of BZD for 90 days; Model 5: chronic use of BZD for 180 da

Table 3. General characteristics of the patients who tested positive for severe acute respiratory syndrome coronavirus 2 (SARS-CoV-2) 


\begin{tabular}{|c|c|c|c|c|c|c|c|c|}
\hline \multirow[t]{2}{*}{ Variables } & \multicolumn{2}{|l|}{ Total } & \multicolumn{2}{|c|}{ Hospital admission $^{\dagger}$} & \multicolumn{2}{|c|}{ Severe outcome ${ }^{\ddagger}$} & \multicolumn{2}{|c|}{ Mortality } \\
\hline & $\mathbf{N}$ & $\%$ & $\mathbf{N}$ & Row \% & $\mathbf{N}$ & Row \% & $\mathbf{N}$ & Row \% \\
\hline Total & 7,596 & $100 \cdot 0$ & 6,019 & $79 \cdot 2$ & 464 & $6 \cdot 1$ & 233 & $3 \cdot 1$ \\
\hline \multicolumn{9}{|c|}{ Benzodiazepine use } \\
\hline No & 6,522 & $85 \cdot 9$ & 5,080 & $77 \cdot 9$ & 353 & $5 \cdot 4$ & 174 & $2 \cdot 7$ \\
\hline Yes & 1,074 & $14 \cdot 1$ & 939 & $87 \cdot 4$ & 111 & $10 \cdot 3$ & 59 & $5 \cdot 5$ \\
\hline \multicolumn{9}{|l|}{ Age } \\
\hline $20-39$ & 2,839 & $37 \cdot 4$ & 1,975 & $69 \cdot 6$ & 58 & $2 \cdot 0$ & 1 & $0 \cdot 0$ \\
\hline $40-59$ & 2,563 & $33 \cdot 7$ & 2,026 & $79 \cdot 0$ & 99 & $3 \cdot 9$ & 16 & $0 \cdot 6$ \\
\hline $60-79$ & 1,795 & $23 \cdot 6$ & 1,622 & $90 \cdot 4$ & 216 & $12 \cdot 0$ & 100 & $5 \cdot 6$ \\
\hline $80+$ & 399 & $5 \cdot 3$ & 396 & $99 \cdot 2$ & 91 & $22 \cdot 8$ & 116 & $29 \cdot 1$ \\
\hline \multicolumn{9}{|l|}{ Sex } \\
\hline Male & 2,992 & $39 \cdot 4$ & 2,464 & $82 \cdot 4$ & 250 & $8 \cdot 4$ & 131 & $4 \cdot 4$ \\
\hline Female & 4,604 & $60 \cdot 6$ & 3,555 & $77 \cdot 2$ & 214 & $4 \cdot 6$ & 102 & $2 \cdot 2$ \\
\hline \multicolumn{9}{|l|}{ Residential Area } \\
\hline Seoul & 501 & $6 \cdot 6$ & 493 & $98 \cdot 4$ & 20 & $4 \cdot 0$ & 3 & $0 \cdot 6$ \\
\hline Gyeonggi-do & 4,971 & $65 \cdot 4$ & 3,521 & $70 \cdot 8$ & 234 & $4 \cdot 7$ & 150 & $3 \cdot 0$ \\
\hline Daegu & 422 & $5 \cdot 6$ & 415 & $98 \cdot 3$ & 41 & $9 \cdot 7$ & 14 & $3 \cdot 3$ \\
\hline Gyeongbuk & 921 & $12 \cdot 1$ & 837 & $90 \cdot 9$ & 101 & $11 \cdot 0$ & 50 & $5 \cdot 4$ \\
\hline Others & 781 & $10 \cdot 3$ & 753 & $96 \cdot 4$ & 68 & $8 \cdot 7$ & 16 & $2 \cdot 0$ \\
\hline \multicolumn{9}{|c|}{ Type of Insurance Coverage } \\
\hline $\mathrm{NHI}$ (community) & 2,048 & $27 \cdot 0$ & 1,606 & $78 \cdot 4$ & 115 & $5 \cdot 6$ & 66 & $3 \cdot 2$ \\
\hline NHI (workplace) & 4,898 & $64 \cdot 5$ & 3,855 & $78 \cdot 7$ & 293 & $6 \cdot 0$ & 125 & $2 \cdot 6$ \\
\hline Medical aid & 650 & $8 \cdot 6$ & 558 & $85 \cdot 8$ & 56 & $8 \cdot 6$ & 42 & $6 \cdot 5$ \\
\hline \multicolumn{9}{|l|}{$\mathrm{CCl}$} \\
\hline 0 & 3,559 & $46 \cdot 9$ & 2,584 & $72 \cdot 6$ & 108 & $3 \cdot 0$ & 22 & $0 \cdot 6$ \\
\hline 1 & 3,291 & $43 \cdot 3$ & 2,749 & $83 \cdot 5$ & 249 & $7 \cdot 6$ & 116 & $3 \cdot 5$ \\
\hline $2+$ & 746 & $9 \cdot 8$ & 686 & $92 \cdot 0$ & 107 & $14 \cdot 3$ & 95 & $12 \cdot 7$ \\
\hline \multicolumn{9}{|l|}{ History of Diabetes } \\
\hline No & 6,409 & $84 \cdot 4$ & 4,917 & $76 \cdot 7$ & 291 & $4 \cdot 5$ & 108 & $1 \cdot 7$ \\
\hline Yes & 1,187 & $15 \cdot 6$ & 1,102 & $92 \cdot 8$ & 173 & $14 \cdot 6$ & 125 & $10 \cdot 5$ \\
\hline \multicolumn{9}{|c|}{ History of Cardiovascular Disease } \\
\hline No & 7,192 & $94 \cdot 7$ & 5,635 & $78 \cdot 4$ & 407 & $5 \cdot 7$ & 183 & $2 \cdot 5$ \\
\hline Yes & 404 & $5 \cdot 3$ & 384 & $95 \cdot 0$ & 57 & $14 \cdot 1$ & 50 & $12 \cdot 4$ \\
\hline \multicolumn{9}{|c|}{ History of Cerebrovascular Disease } \\
\hline No & 7,117 & $93 \cdot 7$ & 5,554 & $78 \cdot 0$ & 395 & $5 \cdot 6$ & 162 & $2 \cdot 3$ \\
\hline Yes & 479 & $6 \cdot 3$ & 465 & $97 \cdot 1$ & 69 & $14 \cdot 4$ & 71 & $14 \cdot 8$ \\
\hline \multicolumn{9}{|l|}{ History of COPD } \\
\hline No & 7,456 & $98 \cdot 2$ & 5,887 & $79 \cdot 0$ & 435 & $5 \cdot 8$ & 200 & $2 \cdot 7$ \\
\hline Yes & 140 & $1 \cdot 8$ & 132 & $94 \cdot 3$ & 29 & $20 \cdot 7$ & 33 & $23 \cdot 6$ \\
\hline \multicolumn{9}{|l|}{ History of Asthma } \\
\hline No & 6,541 & $86 \cdot 1$ & 5,137 & $78 \cdot 5$ & 366 & $5 \cdot 6$ & 172 & $2 \cdot 6$ \\
\hline Yes & 1,055 & $13 \cdot 9$ & 882 & $83 \cdot 6$ & 98 & $9 \cdot 3$ & 61 & $5 \cdot 8$ \\
\hline
\end{tabular}




\begin{tabular}{|c|c|c|c|c|c|c|c|c|}
\hline No & 6,016 & $79 \cdot 2$ & 4,545 & $75 \cdot 5$ & 249 & $4 \cdot 1$ & 67 & $1 \cdot 1$ \\
\hline Yes & 1,580 & $20 \cdot 8$ & 1,474 & $93 \cdot 3$ & 215 & $13 \cdot 6$ & 166 & $10 \cdot 5$ \\
\hline No & 7,528 & $99 \cdot 1$ & 5,953 & $79 \cdot 1$ & 447 & 5.9 & 213 & $2 \cdot 8$ \\
\hline Yes & 68 & 0.9 & 66 & $97 \cdot 1$ & 17 & $25 \cdot 0$ & 20 & $29 \cdot 4$ \\
\hline \multicolumn{9}{|c|}{ NHI: National health insurance, CCl: Charlson Comorbidity Index, COPD: chronic obstructive pulmonary disease, ICU: intensive care ur } \\
\hline \multicolumn{9}{|c|}{${ }^{+}$Hospital admission comprised admission, admission to the intensive care unit, invasive ventilation, or mortality. } \\
\hline
\end{tabular}

\section{Figures}

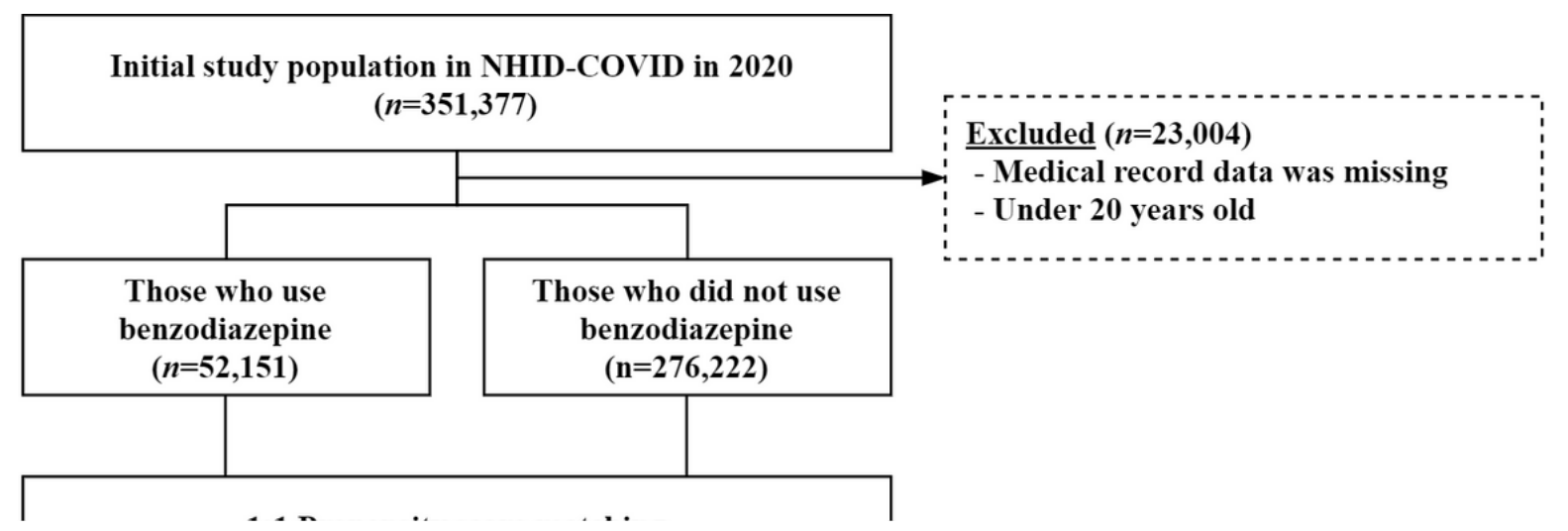

Figure 1

Flowchart showing the selection of the study population. NHID-COVID: National Health Information Database-Coronavirus disease; SARS-CoV-2: severe acute respiratory syndrome coronavirus 2 . 


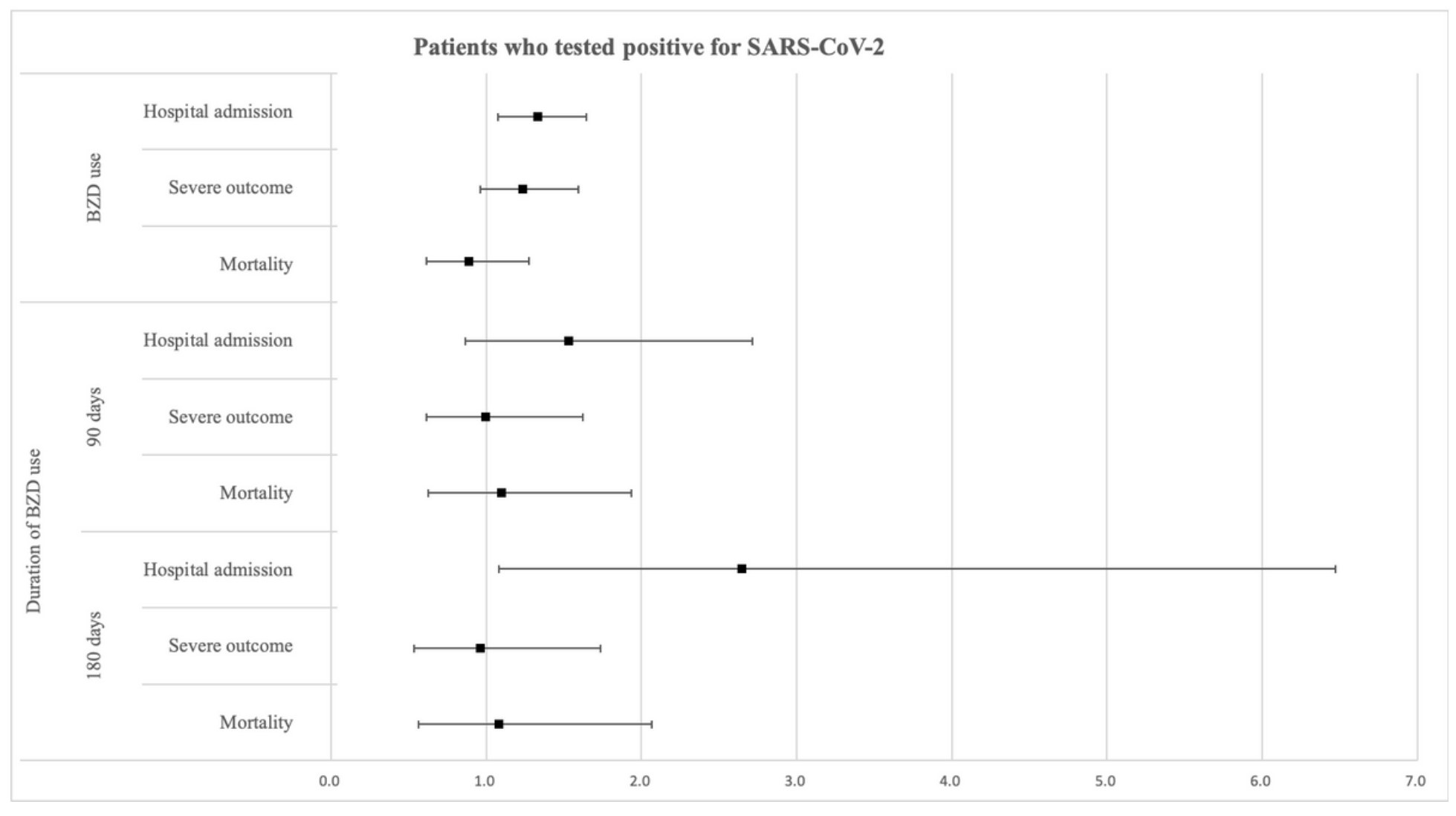

Figure 2

The results of the analysis of the association between benzodiazepine use and clinical outcomes. BZD: benzodiazepine.

\section{Supplementary Files}

This is a list of supplementary files associated with this preprint. Click to download.

- eTable1.xlsx 